\title{
Two-Phase Flow and Pressure Drop in Flow Passages of Compact Heat Exchangers
}

ANL $/ \mathrm{CP}--74646$

DE92 006996

by

M. W. Wambsganss, J. A. Jendrzejczyk, and D. M. France 's

Argonne National Laboratory

\section{ABSTRACT}

Two-phase flow experiments were performed with air/water mixtures in a small rectangular channel measuring $9.52 \times 1.59 \mathrm{~mm}$ (aspect ratio equal to 6), for application to compact heat exchangers. Pressure drop and flow pattern definition data were obtained over a large range of mass qualities (0.0002 to 1$)$ and, in the case of flow pattern data, a large range of mass fluxes (50 to $2,0000 \mathrm{~kg} / \mathrm{m}^{2} \mathrm{~s}$ ). A flow pattern map, based on visual observations and photographs of the flow patterns, is presented and compared with a map developed for a rectangular channel of the same aspect ratio but with dimensions twice those of the test channel, and with a map developed for a circular tube with the same hydraulic diameter of $3 \mathrm{~mm}$. Pressure drop data are presented as a function of both mass quality and Martinelli parameter and are compared with state-of-the-art correlations and a modified Chisholm correlation.

\section{INTRODUCTION}

Compact heat exchangers are used extensively in vehicular applications. Such applications include the heat exchangers used as evaporators and 
condensers in air-conditioning and in refrigerated trucks and trailers. Over the past two decades, there have been tremendous advancements in manufacturing technology. This has allowed the use of different materials and significantly smaller flow passages and has resulted in a new generation of high-performance compact heat exchangers. These heat exchangers typically involve small, noncircular flow passages that have the advantages of high thermal effectiveness, large heat transfer surface-to-volume ratio, low weight per heat transfer duty, reduced fluid inventory, and design flexibility.

Designing refrigerant heat exchangers for smaller overall volume and reduced weight remain goals of the automotive cooling system engineer. The pending replacement of refrigerant $R-12$ with $R-134 a$ provides the current impetus for redesigning and improving the performance of these heat exchangers and for reducing refrigerant inventory; the reduction in fluid inventory is important because, among other things, the replacement refrigerant is expensive.

The advancements in manufacturing technology and materials have surpassed our ability to design an optimal heat transfer surface for a given application, e.g., evaporator or condenser. Compact heat exchangers can accommodate a variety of heat transfer surfaces. At present, optimization of phase-change heat transfer surfaces is an emerging technology; in particular, a validated design technology for phase-change heat transfer in small, noncircular passages is lacking. As a result, new designs typically evolve on the basis of experience, following developments in manufacturing technology.

To expedite development of compact heat exchangers and to allow for design optimization, fundamental studies are required. The overall objective of such studies is to obtain an in-depth understanding and characterization of the 
mechanisms associated with both heat transfer and pressure drop. Included in the fundamental studies is the need for research on two-phase flow patterns and pressure drop, as well as on phase-change (boiling and condensing) heat transfer, with the objective of deveioping flow-pattern-dependent design correlations.

Argonne National Laboratory is engaged in a research program, sponsored by the U.S. Department of Energy, to study multiphase flow and phase-change heat transfer in channels that are representative of compact heat exchangers of the plate-fin type. Understanding and characterizing flow patterns is of fundamental importance to the understanding and modeling of the physics of the heat transfer process. Consequently, a program plan was developed to include studies of two-phase flow dynamics (flow patterns and frictional pressure drop), using gas/liquid mixtures in an adiabatic test apparatus, as well as studies of phase-change heat transfer. As a first step toward obtaining an improved, indepth understanding of two-phase flow in small passages, small, horizontal rectangular channels were chosen for study. The rectangular cross-section was chosen as representative of the noncircular flow passages used in plate-fin heat exchangers. Use of a single channel circumvents the flow maldistribution problems inherent in multichannel flow arrangements.

Results of a literature survey focusing on two-phase flow in rectangular and other noncircular geometries has been summarized by Wambsganss et al. [1-4] and will not be repeated here. In general, the results available in the literature are from channels of larger cross-sectional area. Of the previously reported studies, the work performed by Damianides $[5,6]$ on two-phase flow of air/water mixtures in small-diameter tubes ( 1 to $5 \mathrm{~mm}$ diameter), despite the difference in cross-sectional geometry, is perhaps the most relevant. 
Results from an investigation of two-phase flow of an air/water mixture in a horizontal, rectangular channel with dimensions of $19.05 \times 3.18 \mathrm{~mm}$ (aspect ratio of 6) have been reported by Wambsganss and coworkers [1-4] for the two extreme orientations, i.e., long side vertical and long side horizontal. Flow pattern maps were developed and compared with maps available in the literature for two-phase flow in circular tubes and in rectangular channels of larger size [1-3]. Measured two-phase pressure drop data were used as the basis for evaluating state-of-the-art correlations and developing improved correlations $[1,2,4]$.

The present study is of flow patterns and pressure drop in a channel of onehalf the size of the earlier channel, i.e., $9.52 \times 1.59 \mathrm{~mm}$. A flow pattern map was developed and compared with the map developed for the larger channel and wich a map for a small-diameter tube of comparable cross-sectional area. Frictional pressure drop data were obtained and used to evaluate existing correlations and to establish an improved correlation based on data from the $19.05 \times 3.18 \mathrm{~mm}$ channel.

The focus of this paper is on the development and implementatior of a technology that will lead to energy-efficient, smaller, and lighter heat exchangers (evaporators and condensers) for vehicular applications. Because of the large number of vehicles produced each year, the overall impact on energy savings and cost can be substantial. However, the potential application base for this technology extends far beyond vehicular applications. For example, it is also anticipated that the technology will affect the residential and commercial building air conditioning market. Phasing out CFC refrigerants represents a tremendous challenge to the heating, ventilation, air conditioning, and refrigeration industry. The current alternative refrigerant (HFC-134a) is not a "drop-in," and condensers and evaporators will have to be redesigned. Smaller, more compact, and cost- 
effective evaporators and condensers will clearly add to the edge for U.S. industry in this very large market.

Thus, between vehicular and building applications, the potential for application of the results is quite large. However, the technology also has potential use in space applications because surface tension forces dominate body forces in the very small passages being considered and planned for future study. Process intensification, that is, the design of more compact process plant components, is yet another application that will ultimately result in cost and energy savings.

\section{EXPERIMENTAL APPARATUS}

The experimental apparatus is described in some detail in previous publications $[1,3,4]$ and is summarized here. The apparatus, illustrated schematically in Fig. 1, was designed to allow adiabatic flow experiments with gas/liquid mixtures in channels of small cross-sectional area. A gas (in these experiments, compressed air) flows through a selected gas rotameter to the gas/liquid mixer. Similarly, a liquid (water, in these experiments) flows through a liquid rotameter to the mixer. In the mixer, the air is injected into the water stream through a porous medium. The estimated uncertainty in measurement of flow rate is $\pm 3 \%$. Exiting from the mixer, the two-phase mixture flows either through the test channel to a gas/liquid separator or (in the case of the subject tests) the air is exhausted to the atmosphere and the water flows to a drair.

The test channel, where pressure measurements are made and flow patterns are determined, is shown in Fig. 2. The channel is $0.61 \mathrm{~m}$ long and has a rectangular cross-section with dimensions $9.52 \times 1.59 \mathrm{~mm}$ (aspect ratio of 6). It 
has clear Plexiglass sides to allow flow visualizat on and photography of the twophase flow patterns. Pressure taps are centered on the long side of the channel and spaced along the channel length. Both differential pressure, over a specified channel length, and dynamic pressure, at two locations, were measured. Figure 2 gives locations, relative to the exit of the mixer, of the pressure taps used in the pressure measurements. The estimated uncertainty in pressure measurement was $\pm 5 \%$.

\section{PROCEDURE}

\section{Flow pattern and transitions}

In recognition of the subjectivity associated with determining flow patterns by visual observation, the flow pattern descriptors used in our studies were defined in detail by Wambsganss et al. [1-3]. With these descriptors, flow pattern maps were developed to characterize the two-phase fluid dynamics and ultimately provide a basis for developing flow-pattern-dependent methods of predicting pressure drop and heat transfer. Superficial gas and liquid velocities were used as the map coordinates. Test points were established corresponding to a range of nine different total mass fluxes $(50,100,150,250,350,500,700,1000$, and $2000 \mathrm{~kg} / \mathrm{m}^{2} \mathrm{~s}$ ) and to selected values of mass quality (or superficial gas velocity). The wide range of mass fluxes was chosen to obtain data to cover the entire range of possible two-phase flow patterns. Rotameter settings and other data required to achieve the preselected test conditions were determined with a spreadsheet program developed specifically for experiment design and data analysis.

In addition to visual observations, supplemented with photographic data, an objective method identified by Wambsganss et al. [1] is used to establish the 
transition-to-slug-flow boundary. The method is based on changes in the rootmean-square (RMS) values of the dynamic pressure-time signals when plotted as a function of quality for a specific total mass flux.

\section{Frictional pressure gradient}

To verify the instrumentation and the measurement and analysis methods, single-phase pressure drop was measured and plots for friction factor versus Reynolds number were developed. The experimental results and a comparison with theory for the laminar regime $(f=19.7 / R e)$ and smooth channel results of Blasius for the turbulent regime $\left(f=0.79 \mathrm{Re}^{-0.25}\right)$ are given in Fig. 3. The good agreement shown in Fig. 3 serves to substantiate the validity of the instrumentation and experimental apparatus.

It was recognized in previous investigations [1-4] that flow pattern identification, as well as data analysis and interpretation, are facilitated by systematic testing. Therefore, the same approach was followed in this study. In particular, testing at selected values of total mass flux was performed to allow identification of mass velocity effects and to facilitate the inclusion of such effects in pressure drop correlations. Obtaining data in the low- to very-low-quality range provides the researcher with a data base for studying the effects of flow pattern transitions on pressure (both dynamic-test-section pressure and timeaveraged mean pressure drop); however, such low-quality measurements are inherently difficult. These results have been shown to be important because they are the basis for the objective method of identifying the transition to slug flow pattern [1].

Pressure data were measured for test runs corresponding to selected values of total mass flux ( 50 to $350 \mathrm{~kg} / \mathrm{m}^{2} \mathrm{~s}$ in increments of $50 \mathrm{~kg} / \mathrm{m}^{2} \mathrm{~s}$ ). At each value of 
mass flux, data were obtained at preselected values of mass quality ranging from 0 to 1 , or as high as the test-section design pressure allows. For mass qualities greater than 0.1 , the test increment was 0.05 ; for mass qualities less than 0.1 , the test points were selected to emphasize the range corresponding to the transition to slug flow.

\section{EXPERIMENTAL RESULTS}

\section{Flow patterns and transitions}

Five distinct flow patterns, with descriptors of stratified, plug, slug, wave, and annular, were identified in an earlier study, as discussed above, and detailed definitions of these descriptors are given by Wambsganss et al. in Refs. 1-3. In the present study, these descriptors were again used with the addition of two other descriptors, slow-slugging and churn. These two additional descriptors have been added to further characterize the observed two-phase flow in the $9.52 \mathrm{x}$ $1.59 \mathrm{~mm}$ channel.

Slow-slugging is defined as a pattern in which one or more liquid slugs are transmitted through the channel, followed by a period of essentially "stratified" flow. This phenomenon may be unique to small channels or may be a function of the particular mixer design coupled with flow channel geometry. In small channels, small perturbations at the gas/liquid interface in stratified flow can produce a slug of liquid that bridges the long dimension of the channel. If the slug was generatea intermittently with a relatively long time period, rather than regularly, the flow pattern was termed slow-slugging. As channels become smaller, it is anticipated that slow-slugging may completely eliminate the stratified flow pattern. 
The churn flow pattern descriptor is used to characterize vertical two-phase flow. As defined by Collier [7], churn flow is formed by the breakdown of the large gas bubbles in slug flow, with the gas flowing in a more or less chaotic manner through the liquid, which is mainly displaced to the channel wall. It is speculated that churn flow is observed in the horizontal channel of these experiments because the channel is sufficiently small that surface tension forces tend to dominate over gravity forces at higher values of mass flux and superficial gas velocities.

A typical flow pattern photograph from each of the flow pattern categories is given in Fig. 4, where key features of these patterns can be observed.

As described in Refs. 1-3, Wambsganss et al. proposed an objective method for identifying the transition-to-slug-flow boundary. It was determined that the transition to slug flow occurs in the quality range corresponding to a well-defined breakpoint in the curve of RMS channel pressure versus mass quality as mass quality is increased from a low value, e.g., 0.001 . The flow pattern map, developed on the basis of visual observations and application of the RMS pressure-versusquality data, is given in Fig. 5. It should be noted that the transition boundaries delineating the various flow patterns are typically not sharp lines, as indicated on the map, but have "width," and in most cases there is a gradual transition between patterns.

\section{Frictional pressure gradient}

The frictional pressure gradient data were analyzed using the concept of two-phase multipliers. Two multipliers are used in this study: 


$$
\phi_{\mathrm{FL}}^{2}=\mathrm{DpF} / \mathrm{DpFL}
$$

and

$$
\phi_{\mathrm{FLO}}^{2}=\mathrm{DPF} / \mathrm{DpFLO}
$$

where $\mathrm{DpF}$ is the measured two-phase frictional pressure gradient and DpFL and DpFLo are the frictional pressure gradients corresponding, respectively, to the cases of the liquid flowing alone in the channel and the total mixture flowing as a liquid. These multipliers are typically plotted versus mass quality $\mathbf{x}$ or the Martinelli parameter X, where

$$
\mathrm{X}=\left(\mathrm{DpFL} / \mathrm{DpFG}^{2}\right.
$$

and $\mathrm{DpFG}$ is the frictional pressure gradient corresponding to the case of the gas flowing alone in the channel.

Following Lockhart and Martinelli [8], the square roct of the two-phase multiplier $\phi_{\mathrm{FL}}^{2}$ is plotted as a function of the Martinelli parameter X in Fig. 6 . Over the range of mass flow rates tested, i.e., to $350 \mathrm{~kg} / \mathrm{m}^{2} \mathrm{~s}$, the flow regime associated with the liquid flowing alone is always laminar. However, the relationship for $\mathrm{X}$ will vary, as determined by Eq. 3, because laminar and turbulent regimes are calculated for the gas phase flowing alone in the channel.

The two-phase multiplier $\phi_{\text {FLO }}^{2}$ is plotted as a function of mass quality $\mathbf{x}$ in Fig. 7. In Fig. 7a, a logarithmic scale is used for the mass quality to accentuate the results in the low-quality range $(0.0001$ to 0.1$)$; it is generally in this range of mass quality that the various flow pattern transitions occur. In Fig. 7b, a linear scale is used, in this case to emphasize the data in the high-quality range ( 0.1 to 
1), which, for the most part, is the range of practical interest for evaporator design.

\section{ANALYSIS}

\section{Flow patterns and transitions}

The flow pattern map developed for the $9.52 \times 1.59 \mathrm{~mm}$ channel is given in Fig. 5 and is compared with the map for the $19.05 \times 3.59 \mathrm{~mm}$ channel in Fig. 8. In comparing the two flow pattern maps in Fig. 8, the following general observations can be made relative to the smaller channel: (a) the trends in flow pattern transitions are the same for the two channels, (b) the transition-to-slug and transition-to-annular boundaries are shifted to the right, i.e., to a higher value of superficial gas velocity, (c) two additional flow pattern descriptors (slow-slugging and churn) are required to characterize the observe flow patterns, and (d) a bubble flow pattern is not observed.

It is also of interest to determine how the flow pattern map presented in Fig. 5 compares with a map for air/water mixtures in a circular channel of comparable size. Damianides [5,6] developed flow pattern maps for air/water mixtures in capillary tubes with diameters ranging from 1 to $5 \mathrm{~mm}$. In Fig. 9, the map for the $9.52 \times 1.59 \mathrm{~mm}$ channel (hydraulic diameter equal to $2.92 \mathrm{~mm}$ ) is compared with the Damianides map for a $3 \mathrm{~mm}$ tube. Except that no bubble flow pattern is observed in the smaller channel, the two maps are in reasonable agreement insofar as the general trends exhibited are similar. In particular, a wave pattern is observed between the slug and annular flow patterns at the lower values of superficial liquid velocity. Damianides identifies a pseudo-slug pattern between the slug and annular flow patterns at higher values of superficial liquid 
velocity; he defines the pseudo-slug pattern as being similar to annular flow, but with slugs forming periodically as a result of the liquid film being thicker at the bottom than at the top of the tube. The Damianides pseudo-slug pattern appears to be comparable to the churn pattern identified in the subject investigation.

While the general trends and basic flow patterns identified are the same for the two maps of Fig. 9, there are differences. In particular, the transition from plug to slug flow occurs at a higher value of superficial gas velocity on the Damianides map. Here, it should be noted that of all the various transitions, the greatest confidence is in the transition-to-slug-flow boundary, because it is more abrupt and, more important, its identification uses an objective method based on RMS pressure, as discussed above. Relative to the Damianides map, the wave flow pattern region of the $9.52 \times 1.59 \mathrm{~mm}$ channel is shifted up and the churn (pseudo-slug) flow pattern region is shifted to the right. There is relatively good agreement with the transition to annular flow boundary. The lack of identification of a bubble pattern for the $9.52 \times 1.59 \mathrm{~mm}$ channel versus identification of a bubble pattern in the $3 \mathrm{~mm}$ tube by Damianides may be due in part to differences in the definitions used for bubble flow and in the subsequent interpretation of the observed flow pattern. In this study, bubble flow is defined as dispersed vapor distributed as discrete small bubbles (generally uniform in size) in a continuous liquid phase.

\section{Friction pressure gradient}

The objectives of this study included evaluation and, as necessary, improvement of two-phase frictional pressure gradient correlations. In the study of the $19.05 \times 3.18 \mathrm{~mm}$ channel, widely used correlations from Chisholm $[9,10]$ and Friedel [11] were evaluated. Both correlations were developed primarily from circular tube data and, for the most part, for annular flow. 
The Chisholm correlation, developed from an elementary separated flow model by Chisholm $[9,10]$ to represent the Martinelli circular-tube data, is given by

$$
\phi_{\mathrm{FL}}^{2}=1+\frac{\mathrm{C}}{\mathrm{X}}+\frac{1}{\mathrm{X}^{2}}
$$

where $\phi_{\mathrm{FL}}^{2}$ is the two-phase multiplier given by Eq. 1, and $\mathrm{X}$ is ise Martinelli parameter given by Eq. 3. The C-factor (C-coefficient) of Eq. 4 is dependent on, among other things, the physical properties of the mixture. Collier [7] noted that "... this equation can be used quite generally for the correlation of two-phase pressure data." In particular, the C-factor can be adjusted to give a best fit to a given set of data. For example, the values of the C-factor given in Table 1 [7], used with Eq. 4, provide approximations of the two-component, two-phase, circulartube data of Lockhart and Martinelli [8] for the various listed combinations of flow regimes (laminar or turbulent). (Laminar-to-turbulent transition is typically determined experimentally from single-phase tests.) This correlation was considered with the current experimental results because of its successful application to a large amount of tube data.

A more recent correlation (recommended by Hewitt [12] when $\mu_{\mathrm{L}} / \mu_{\mathrm{G}}<1000$, and highlighted in a handbook for plate-fin heat exchanger design [13]) was developed by Friedel [11]. The Friedel correlation, developed for both horizontal flow and vertical upflow, and based on a data bank of some 25,000 points (3\% of which were obtained from rectangular channels), is given by

$$
\phi_{\mathrm{FLO}}^{2}=\mathrm{E}+\frac{3.24 \mathrm{FH}}{\mathrm{Fr}^{0.045} \mathrm{We}^{0.035}}
$$

where 


$$
\begin{aligned}
& E=(1-x)^{2}+x^{2}\left(\frac{v_{G}}{v_{L}}\right)\left(\frac{f_{G O}}{f_{L O}}\right) \\
& F=x^{0.78}(1-x)^{0.24}, \\
& H=\left(\frac{v_{G}}{v_{L}}\right)^{0.91}\left(\frac{\mu_{G}}{\mu_{L}}\right)^{0.19}\left(1-\frac{\mu_{G}}{\mu_{L}}\right)^{0.7}, \\
& F r=\frac{G^{2} v_{T P}^{2}}{g D_{h}} \\
& W e=\frac{G^{2} D_{h} v_{T P}}{\sigma},
\end{aligned}
$$

and the two-phase specific volume is

$$
\mathrm{v}_{\mathrm{TP}}=\left[\mathrm{xv}_{\mathrm{G}}+(1-\mathrm{x}) \mathrm{v}_{\mathrm{L}}\right]
$$

As can be observed from Eq. 5, the correlation is a function of mass flux G and fluid properties that include viscosities $\mu_{\mathrm{G}}$ and $\mu_{\mathrm{L}}$, surface tension $\sigma$, and specific volumes $\mathrm{v}_{\mathrm{G}}$ and $\mathrm{v}_{\mathrm{L}}$.

Results of the earlier study of the $19.05 \times 3.18 \mathrm{~mm}$ channel demonstrated that neither correlation did a satisfactory job of predicting pressure gradient over the entire parameter range of the experimants. Consequently, a modified version of the Chisholm correlation was developed [1,3] in which the C-factor was made a function of Martinelli parameter and total mass flux,

$$
\mathrm{C}=\mathrm{f}\left(\mathrm{X}, \mathrm{Re}_{L} O\right)=\mathrm{aX}^{\mathrm{b}}
$$

where $\mathrm{a}=\mathrm{f}\left(\operatorname{Re}_{L O}\right)=-2.44+0.00939 \operatorname{Re}_{L O}, \mathrm{~b}=\mathrm{f}\left(\operatorname{Re}_{L O}\right)=-0.938+0.00432 \operatorname{Re}_{L O}$, and $\operatorname{Re}_{L O}$ is the Reynolds number for the mixture flowing as a liquid $\left(=G_{\mathrm{h}} / \mu_{L}\right)$. Equation 6 is valid for $\operatorname{Re}_{L O},<2200$ and $\mathrm{X}<1.0$. 
The RMS percent error in applying the original Chisholm and Friedel correlations to the $9.52 \times 1.59 \mathrm{~mm}$ channel of this study is given in Table 2 as a function of total mass flux. Frum this table, it can be concluded that the Friedel correlation is not generally acceptable; RMS errors range from $700 \%$ at a mass flux of $50 \mathrm{~kg} / \mathrm{m}^{2} \mathrm{~s}$ to $49 \%$ at a mass flux of $350 \mathrm{~kg} / \mathrm{m}^{2} \mathrm{~s}$. The Chisholm correlation based on $\mathrm{C}$ values determined from Table 1, on the other hand, gives RMS errors in the range $70 \%$ for a mass flux of $50 \mathrm{~kg} / \mathrm{m}^{2} \mathrm{~s}$ to $23 \%$ at a mass flux of $350 \mathrm{~kg} / \mathrm{m}^{2} \mathrm{~s}$. For a mass flux greater than $100 \mathrm{~kg} / \mathrm{m}^{2} \mathrm{~s}$, these errors can be considered acceptable for two-phase flow predictions based on empirical correlations of this type [12].

The modified Chisholm correlation (Eq. 6) developed by Wambsganss et al $[1,4]$ from data for the $19.05 \times 3.18 \mathrm{~mm}$ channel, was also applied to data for the smaller channel. The RMS errors in application of the modified Chisholm correlation are also given in Table 2. It can be seen from this table that with the exception of the test run at a mass flux of $50 \mathrm{~kg} / \mathrm{m}^{2} \mathrm{~s}$, for which the errors are comparable to the Chisholm correlation and quite large, the correlation is an improvement over the Chisholm correlation, with RMS errors in the range of 10 to $29 \%$.

\section{SUMMARY AND CONCLUSIONS}

To optimize the design of the heat transfer surfaces of compact heat exchangers for use as condensers and evaporators in vehicular air conditioning systems, there is a need for an improved understanding and characterization of the two-phase flow and heat transfer processes. This study addresses the twophase flow phenomena of flow patterns and pressure drop, using adiabatic flows of air/water mixtures in a $9.52 \times 1.59 \mathrm{~mm}$ rectangular channel. 
A flow pattern map was developed on the basis of visual observations and photographs af the two-phase flow. The general trends were found to be similar to those of a flow pattern map developed from a rectangular channel with dimensions twice those of the smaller channel; the flow pattern map for the larger channel had been shown to differ substantially from state-of-the-art maps developed from circular tube data for moderate to large diameters [1-3]. Nevertheless, there were differences in comparison with the larger rectangular channel. In particular, the bubble flow pattern was not found, and two additional flow patterns were added: slow-slugging and churn. It is postulated that the two additional flow patterns are the result of the small size of the channel and the effect of the surface tension forces that are inherently more prominent in small channels.

Pressure drop data were analyzed using the concept of two-phase multipliers, with the data plotted as functions of both Martinelli parameter and total mass flux. These plots indicated a strong mass flux effect. In an evaluation of two widely used correlations for pressure drop, it was shown that the Friedel correlation is clearly not applicable for two-phase flow in these small rectangular channels. The Chisholm correlation, however, did a reasonable job of correlating the data, except at the lowest mass fluxes. The modified Chisholm correlation, which was developed to correlate the data from a rectangular channel of twice the size, was shown to do a very good job of correlating the data from the smaller rectangular channel at all but the lowest mass flux tested $\left(50 \mathrm{~kg} / \mathrm{m}^{2} \mathrm{~s}\right)$.

The results from this study provide a tool for design analysts to use in calculating pressure drop, as well as insights relative to the flow patterns that can be expected during the phase-change heat transfer process in small rectangular channels. The latter is important to the understanding of the heat 
transfer process and the development of flow-pattern-dependent heat transfer correlations.

\section{ACKNOWLEDGMENTS}

The authors acknowledge Dr. N. T. Obot for his contributions during the initial phases of this research activity, Mr. R. K. Smith for his contributions in the fabrication of the flow apparatus and in the conduct of the experiments, and Ms. Joyce Stephens for help in preparing the manuscript and associated graphics.

This research was funded by the U.S. Departmen f Energy, Office of Conservation and Renewable Energy, Division of Advanced industrial Concepts, and represents a U.S. contribution to Annex I of the International Energy Agency (IEA) Program on Research and Development in Heat Transfer and Heat Exchangers.

\section{REFERENCES}

1. Wambsganss, M. W., Jendrzejczyk, J. A., France, D. M., and Obot, N. T., "Two-Phase Flow Patterns and Frictional Pressure Gradients in a Small, Horizontal, Rectangular Channel," Argonne National Laboratory Report ANL-90/19, May 1990.

\section{DISCLAIMER}

This report was prepared as an acinunt of work sp nsored by an agency of the United States Government. Neitier the United States Gnvernment nor any agency thereof, nor any of their employees, makes any warranty, express or implied, or assuriles any legal liability or responsibility for the accuracy, completeness, or usefulness of any information, apparatus, product, or process disclosed, or represents that its use would not infringe privately owned rights. Reference herein to any specific commercial product, process, or service by trade name, trademark, manufacturer, or otherwise does not necessarily constitute or imply its endorsement, recommendation, or favoring by the United States Government or any agency thereof. The views and opinions of authors expressed herein do not necessarily state or reflect those of the United States Government or any agency thereof. 
2. Wambsganss, M. W., Jendrzejczyk, J. A., France, D. M., and Obot, N. T., "Two-Phase Flow Patterns and Transitions in a Small Rectangular Channel: A Comparison between Two Horizontal Orientations," Argonne National Laboratory Report ANL-90/46, November 1990.

3. Wambsganss, M. W., Jendrzejczyk, J. A., and France, D. M., "Two-Phase Flow Patterns and Transitions in a Small, Horizontal, Rectangular Channel," Int. J. Multiphase Flow, 17(3), 327-342, 1991.

4. Wambsganss, M. W., Jendrzejczyk, J. A., France, D. M., and Obot, N. T., "Frictional Pressure Gradients in Two-Phase Flow in a Small, Horizontal, Rectangular Channel," accepted for publication in Exp. Thermal and Fluid Science J., 1991.

5. Damianides, C. A., "Horizontal Two-phase Flow of Air-water Mixtures in Small Diameter Tubes and Compact Heat Exchangers," University of Mlinois at Urbana-Champaign, Ph.D. Dissertation, 1987.

6. Damianides, C. A., and Westwater, J. W., "Two-phase Flow Patterns in a Compact Heat Exchanger and in Small Tubes," Proc. 2nd U.K. National Conference on Heat Transfer, Glasgow, Scotland, Vol. II, 1257-1268, 1988.

7. Collier, J. G., Convective Boiling and Condensation, New York, McGrawHill Book Co., 2nd Ed, 1981.

8. Lockhart, R. W., and Martinelli, R. C., "Proposed Correlation of Data for Isothermal Two-phase Two-component Flow in Pipes," Chem. Engng Progress 45(1), 39-48, 1949. 
9. Chisholm, D., "A Theoretical Basis for the Lockhart-Martinelli Correlation for Two-phase Flow," Int. J. Heat and Mass Transfer 10, 1767-1778, 1967.

10. Chisholm, D., "Pressure Gradients Due to Friction during the Flow of Evaporating Two-phase Mixtures in Smooth Tubes and Channels," Int. J. Heat Mass Transfer 16(2), 347-358, 1973.

11. Friedel, L., "Improved Friction Pressure Drop Correlation for Horizontal and Vertical Two-phase Pipe Flow," Paper 2, European Two-phase Flow Group Meeting, Ispra, Italy, 1979.

12. Hewitt, G. F., "Measurement of Heat Transfer Coefficient," Handbook of Multiphase Systems, G. Hetsroni, ed., Hemisphere Publishing Corp., Washington, D.C., pp. 10-33-10-44, 1982.

13. Heat Transfer and Fluid Flow Service, Plate-fin Heat Exchangers: Guide to their Specification and Use, M.A. Taylor, ed., 1st Ed., Harwell Laboratory, Oxon, U.K, 1987. 
Table 1. C-factor as a function of flow regimes [7]

\begin{tabular}{lccc}
\hline \multicolumn{2}{c}{ Flow Regime } & & \\
(Liquid-Gas) & Descriptor & C-factor \\
\hline viscous - viscous & vv & 5 \\
turbulent - viscous & tv & 10 \\
viscous - turbulent & vt & 12 \\
turbulent - turbulent & tt & 20 \\
\hline
\end{tabular}


Table 2. RMS percent error $(0.05<x<0.95)$

\begin{tabular}{cccc}
\hline & $\begin{array}{c}\text { Chisholm } \\
\text { Correlation } \\
\text { (Eq. 4) }\end{array}$ & $\begin{array}{c}\text { Friedel } \\
\text { Correlation } \\
\text { (Eq. 5) }\end{array}$ & $\begin{array}{c}\text { Modified } \\
\text { Chisholm } \\
\text { Corr. (Eqs. 4 \& 6) }\end{array}$ \\
\hline 50 & 70 & 700 & 73 \\
100 & 47 & 385 & 29 \\
150 & 27 & 222 & 19 \\
200 & 16 & 132 & 18 \\
250 & 22 & 96 & 14 \\
300 & 25 & 66 & 11 \\
350 & 23 & 49 & 10 \\
& & & \\
\hline
\end{tabular}


Figure captions -

1 Schematic illustration of experimental apparatus.

2 Flow channel (length dimension is in $\mathrm{mm}$ ). Dp is measured pressure drop, $P_{1}$ and $P_{2}$ are measured absolute pressures, and $P_{x}$ is calculated.

3 Single-phase friction factor data for air and water flow in test channel and expected theoretical (laminar regime)/Blasius (turbulent regime) results.

4 Photographs of representative flow patterns for each flow pattern descriptor.

$5 \quad$ Flow pattern map for $9.52 \times 1.59 \mathrm{~mm}$ channel.

6 Two-phase frictional pressure gradient as a function of Martinelli parameter.

7 Two-phase frictional pressure gradient as a function of mass quality: (a) low mass qualities; (b) high mass qualities.

8 Comparison of flow pattern maps: — $9.52 \times 1.59 \mathrm{~mm}$ channel; - - - $19.05 \times 3.18 \mathrm{~mm}$ channel (underlined flow pattern designations are associated with $19.05 \times 3.18 \mathrm{~mm}$ channel data).

9 Comparison of $9.52 \times 1.59 \mathrm{~mm}$ channel map (Fig. 5) with Damianides map for $3 \mathrm{~mm}$ tube: $9.52 \times 1.59 \mathrm{~mm}$ channel; - - - - $19.05 \times 3.18 \mathrm{~mm}$ channel (underlined flow pattern designations are associated with Damianides' data). 


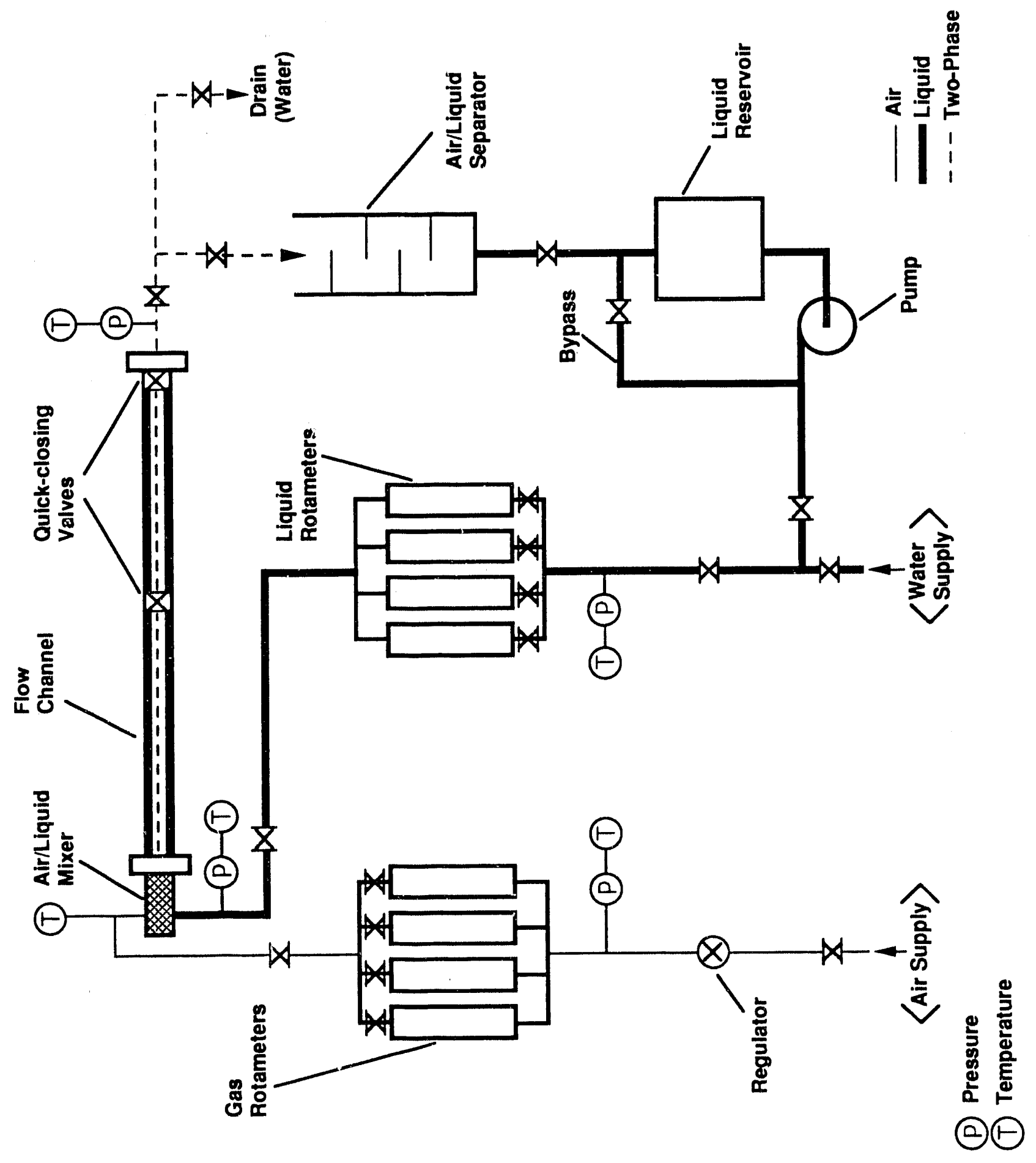




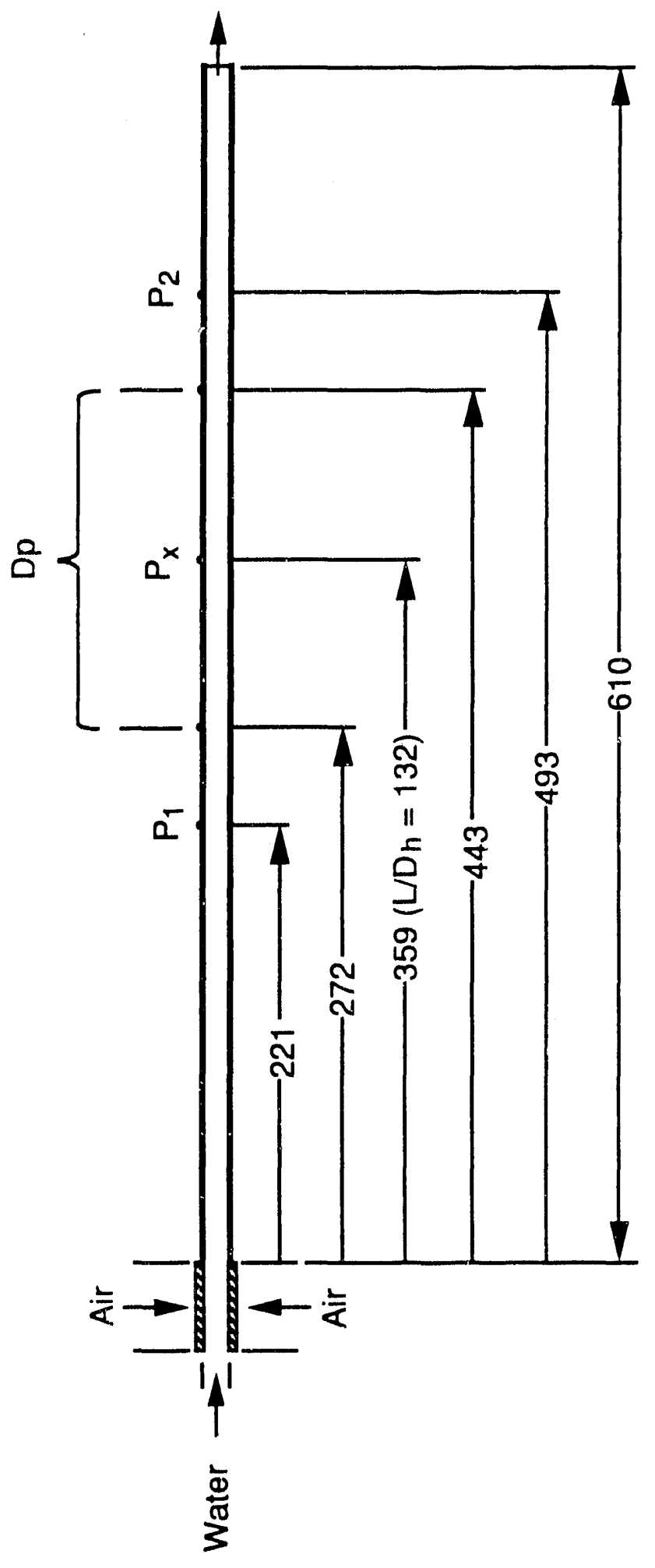




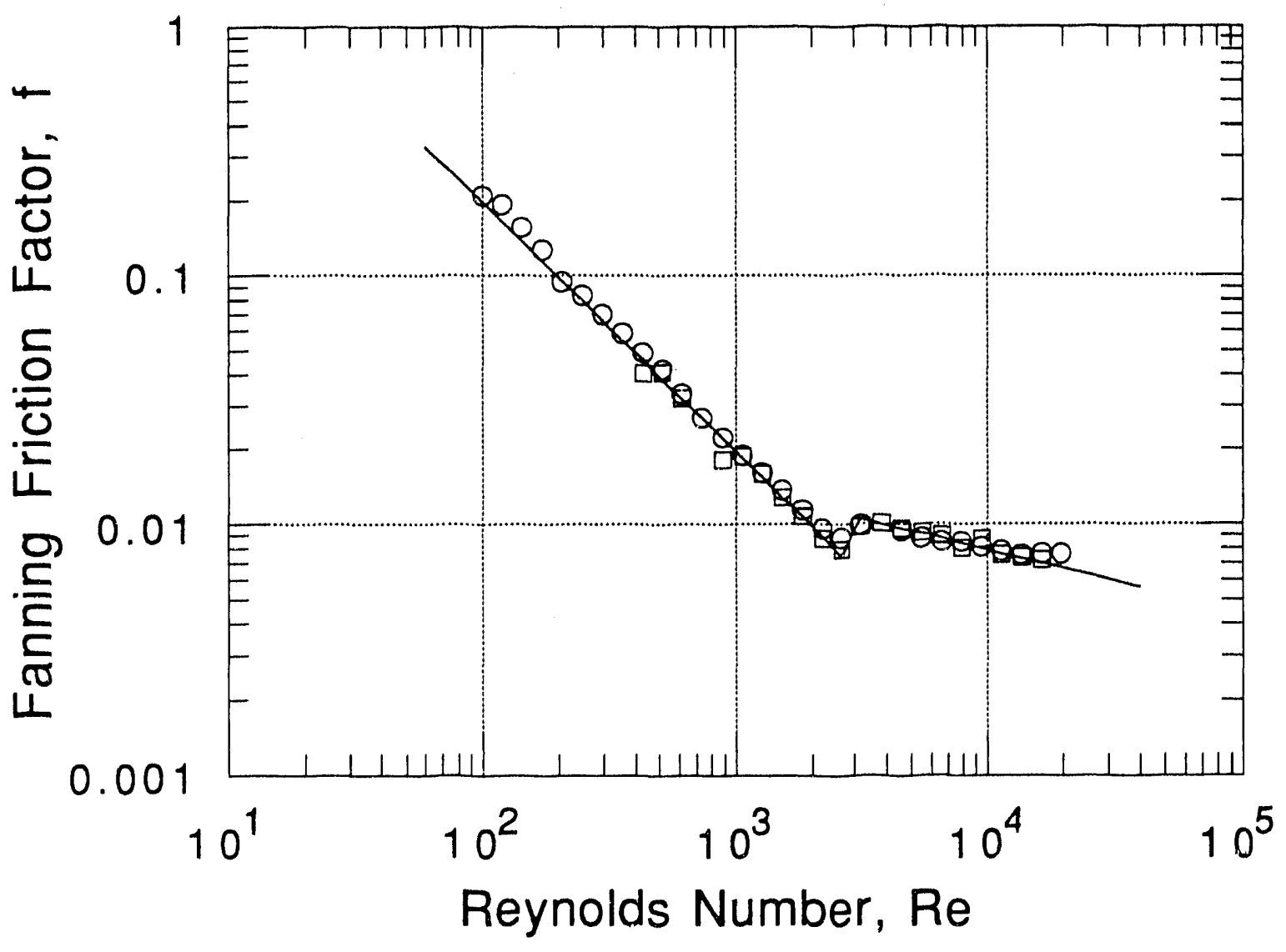



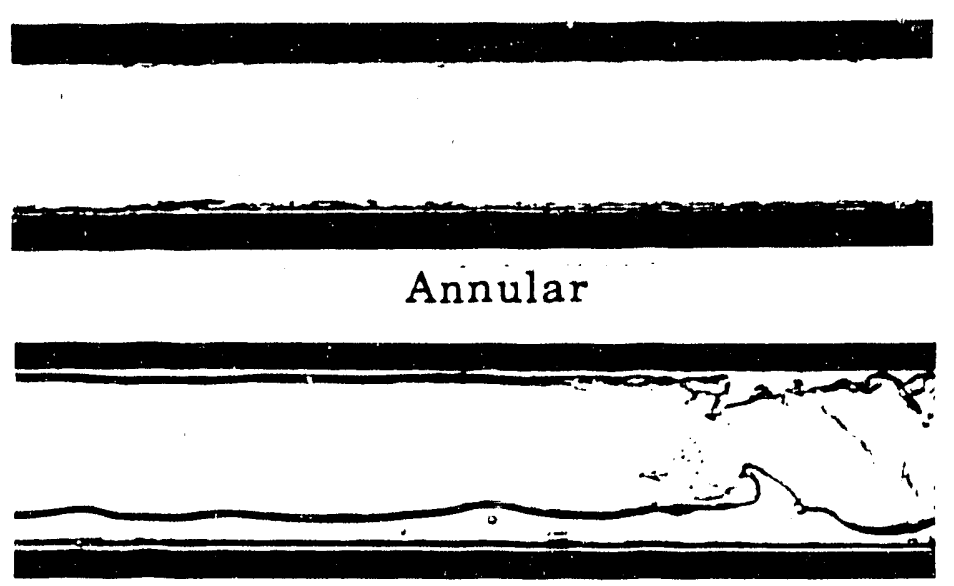

\section{Churn}

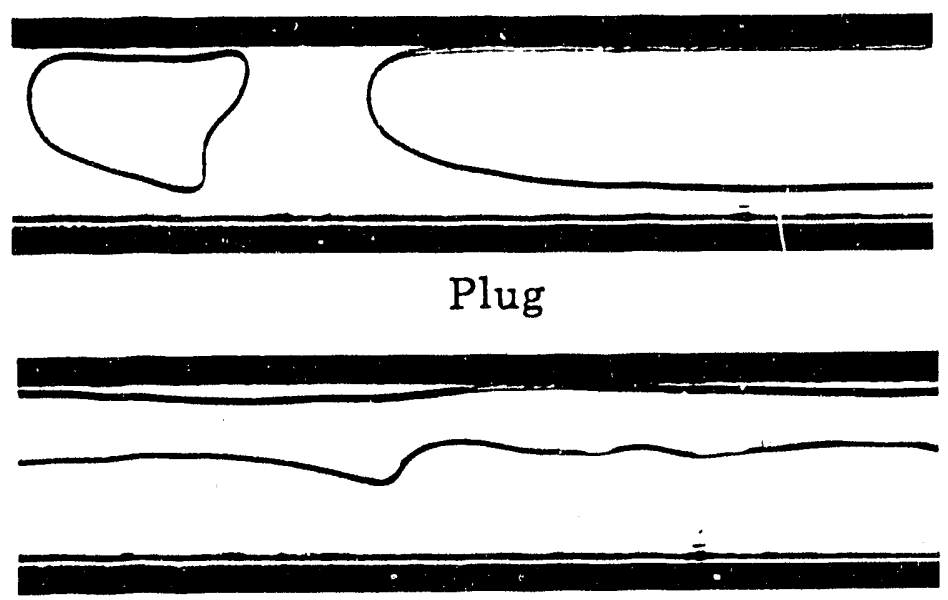

250

Slow-slugging

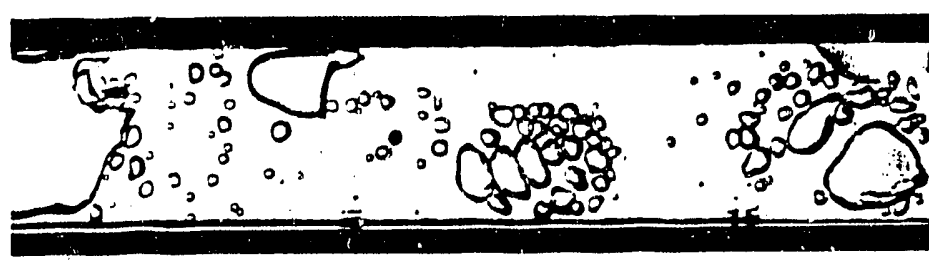

Slug 


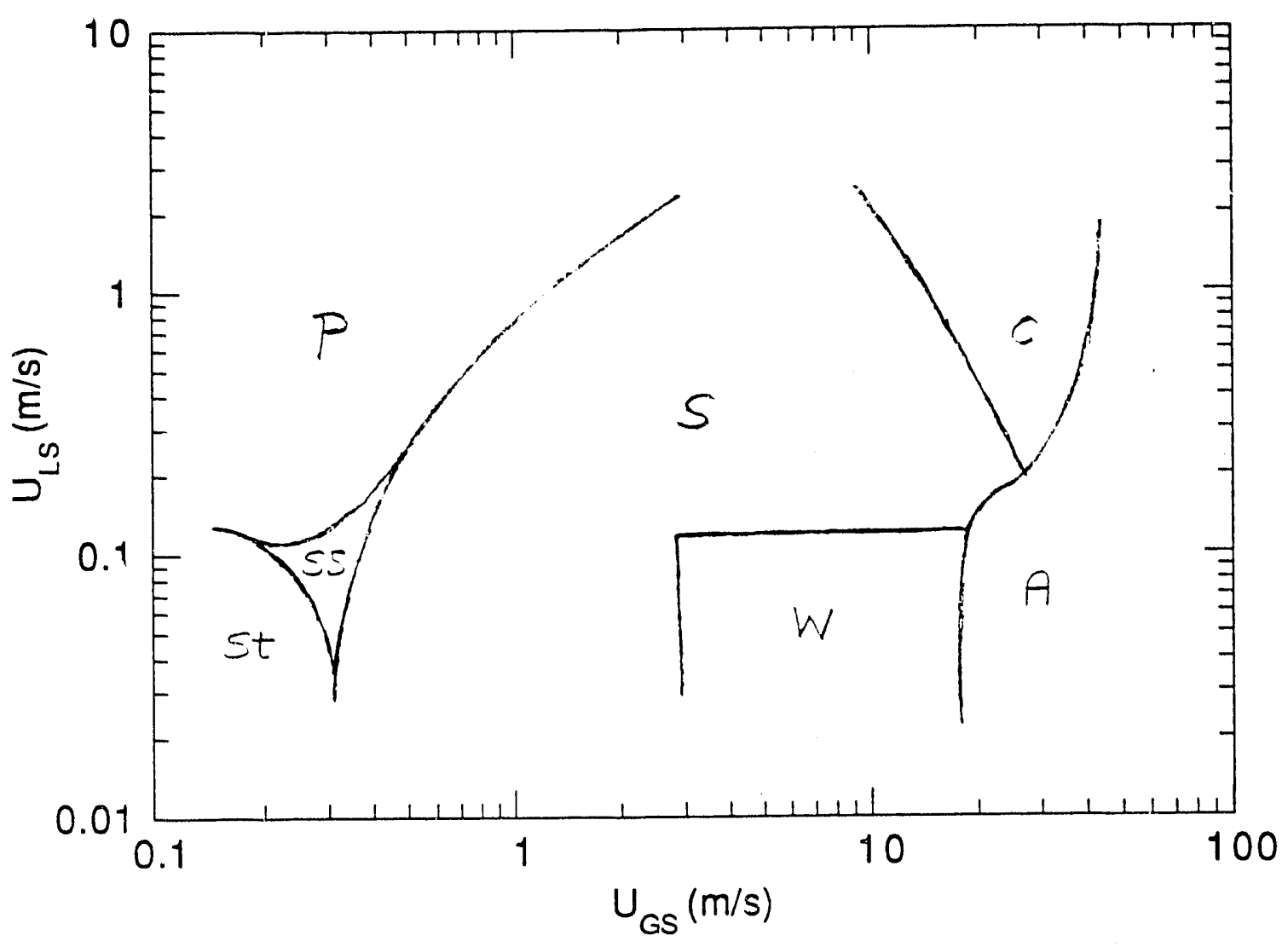
A - Annular
S - Slug
C - Churn
St - Stratified
$P$ - Plug
W - Wave
SS - Slow-slugging 


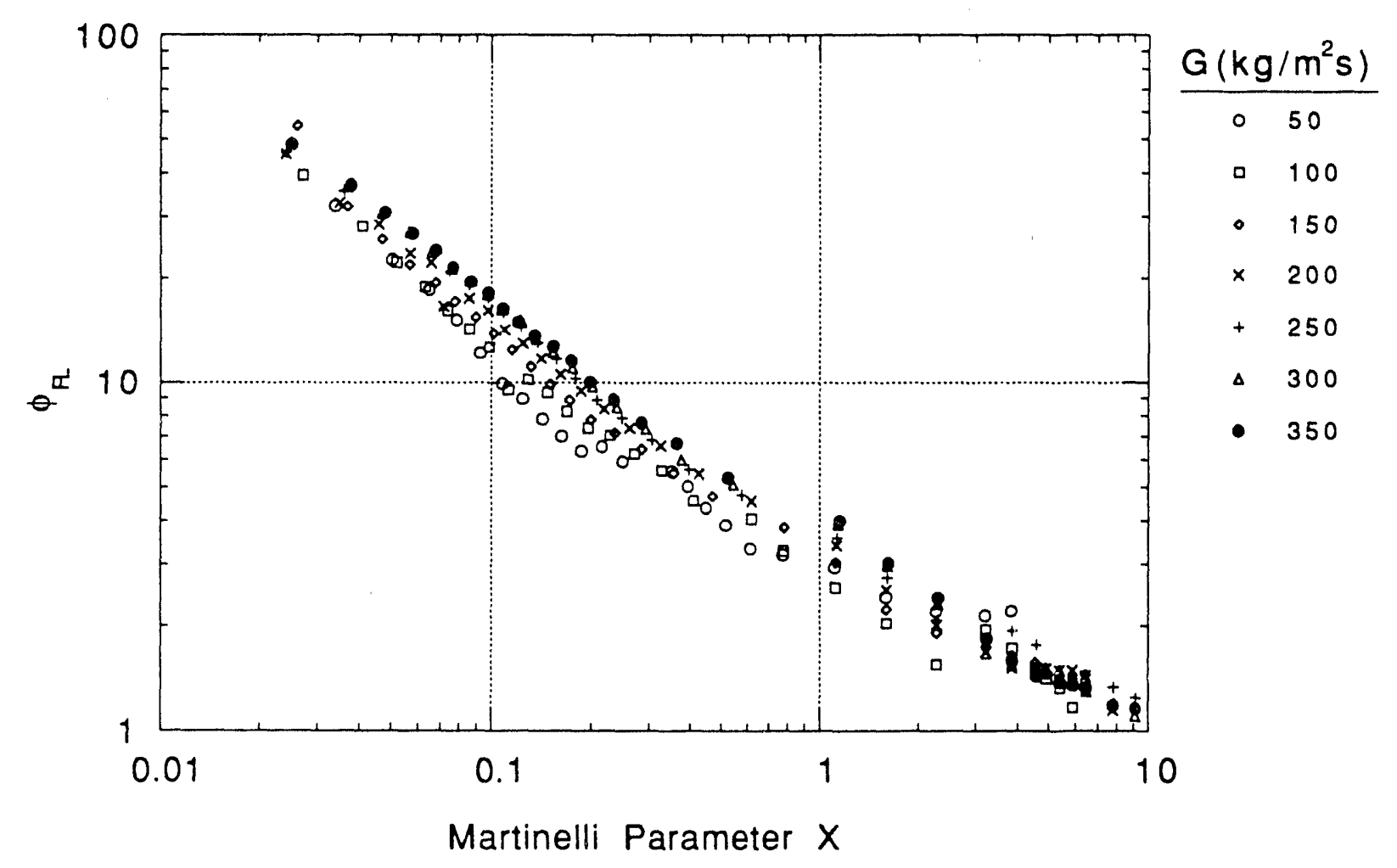




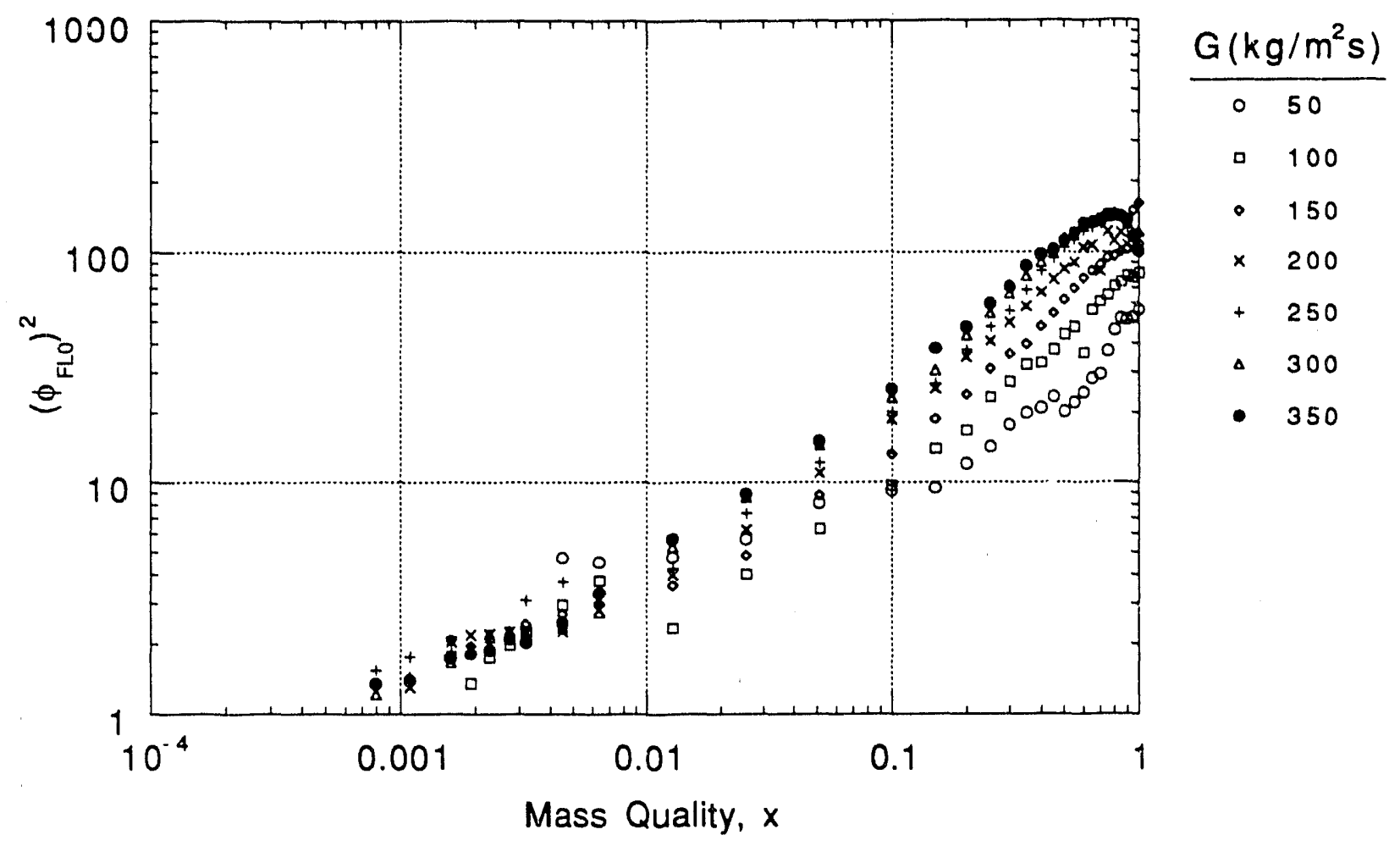

(a)

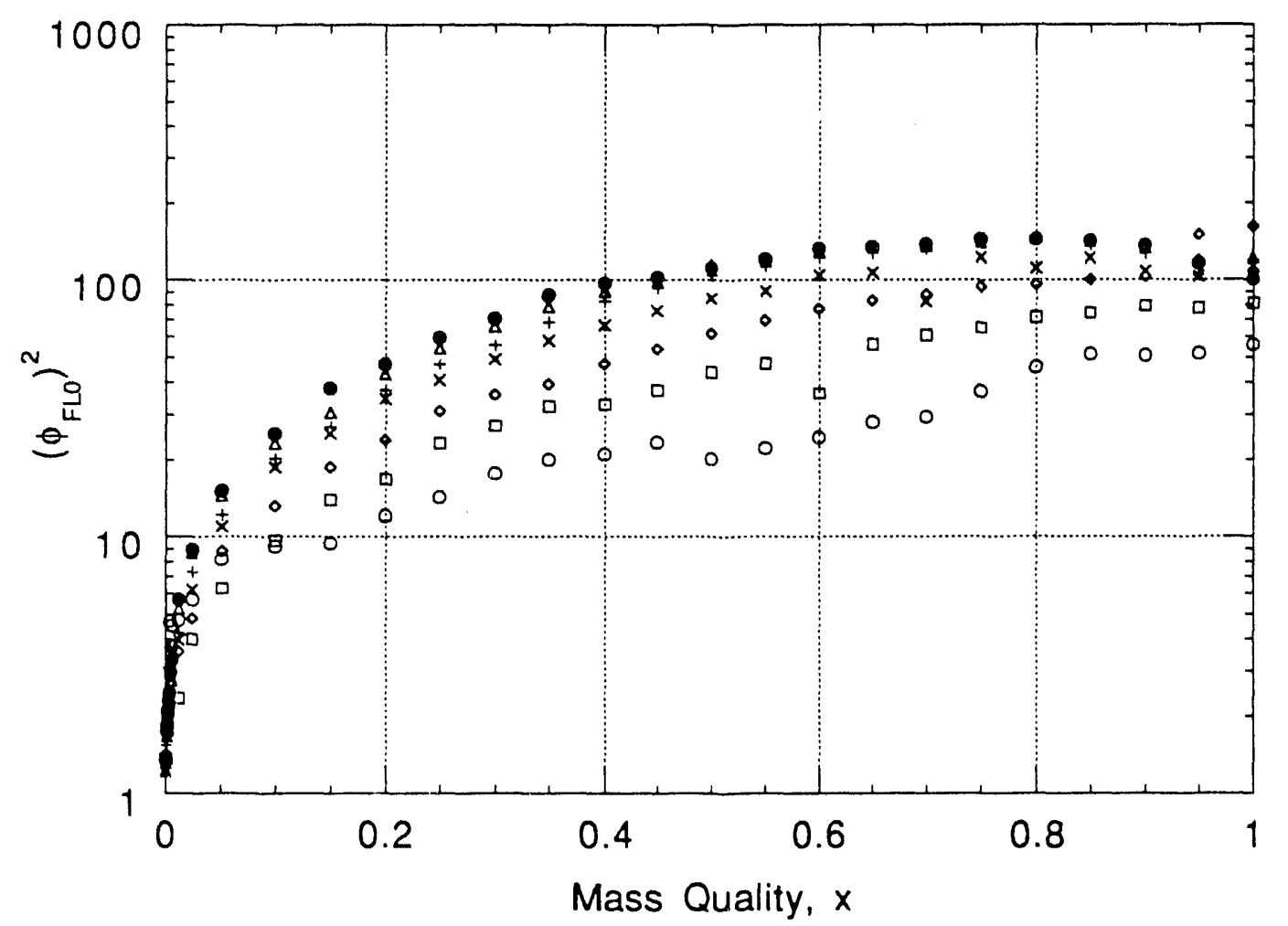

(b) 



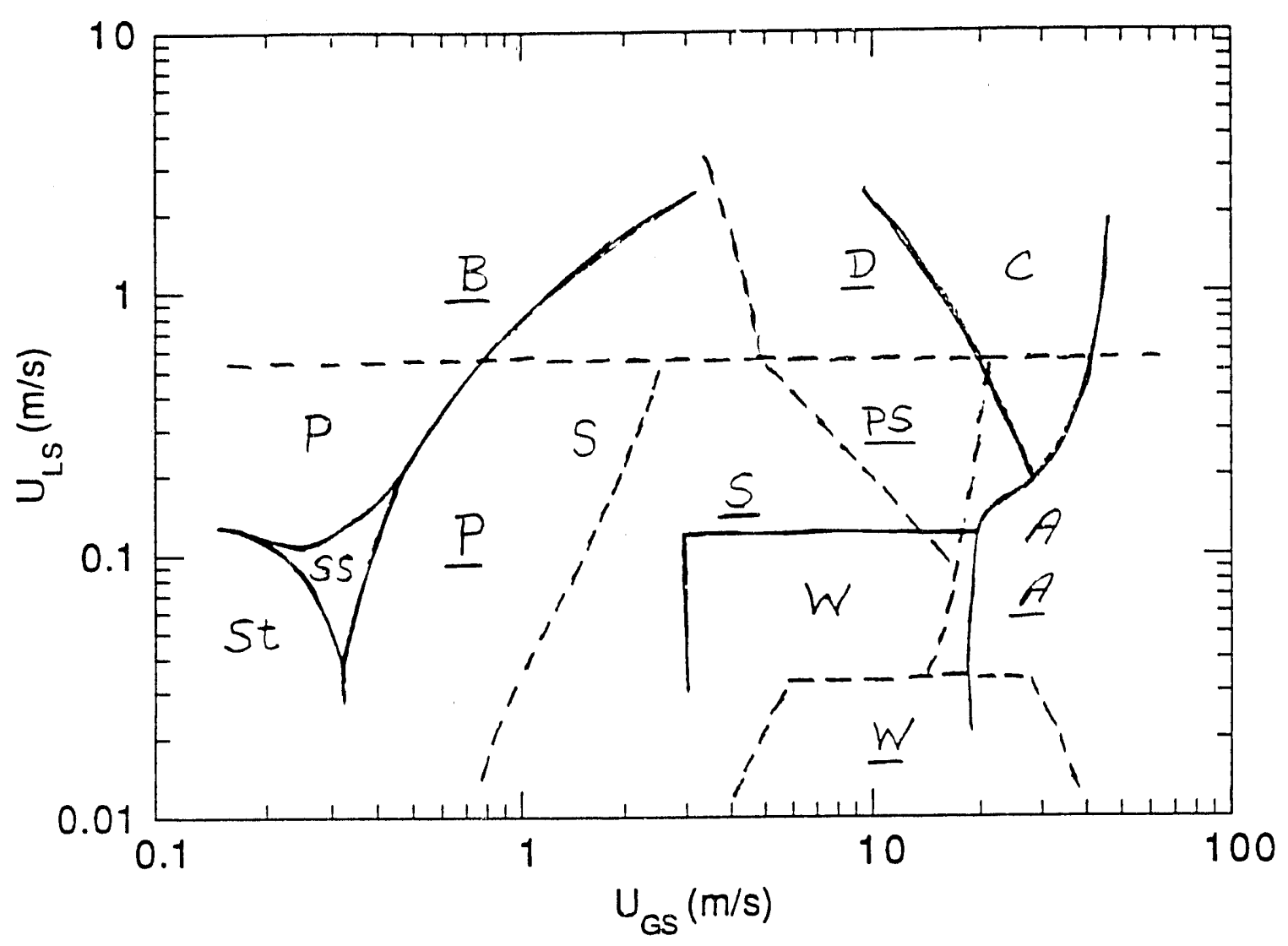
A - Annular
B - Bubble
C - Churn
D - Dispersed
$P$ - Plug

PS - Pseudo-slug

SS - Slow-slugging

S - Slug

St - Stratified

W - Wave 

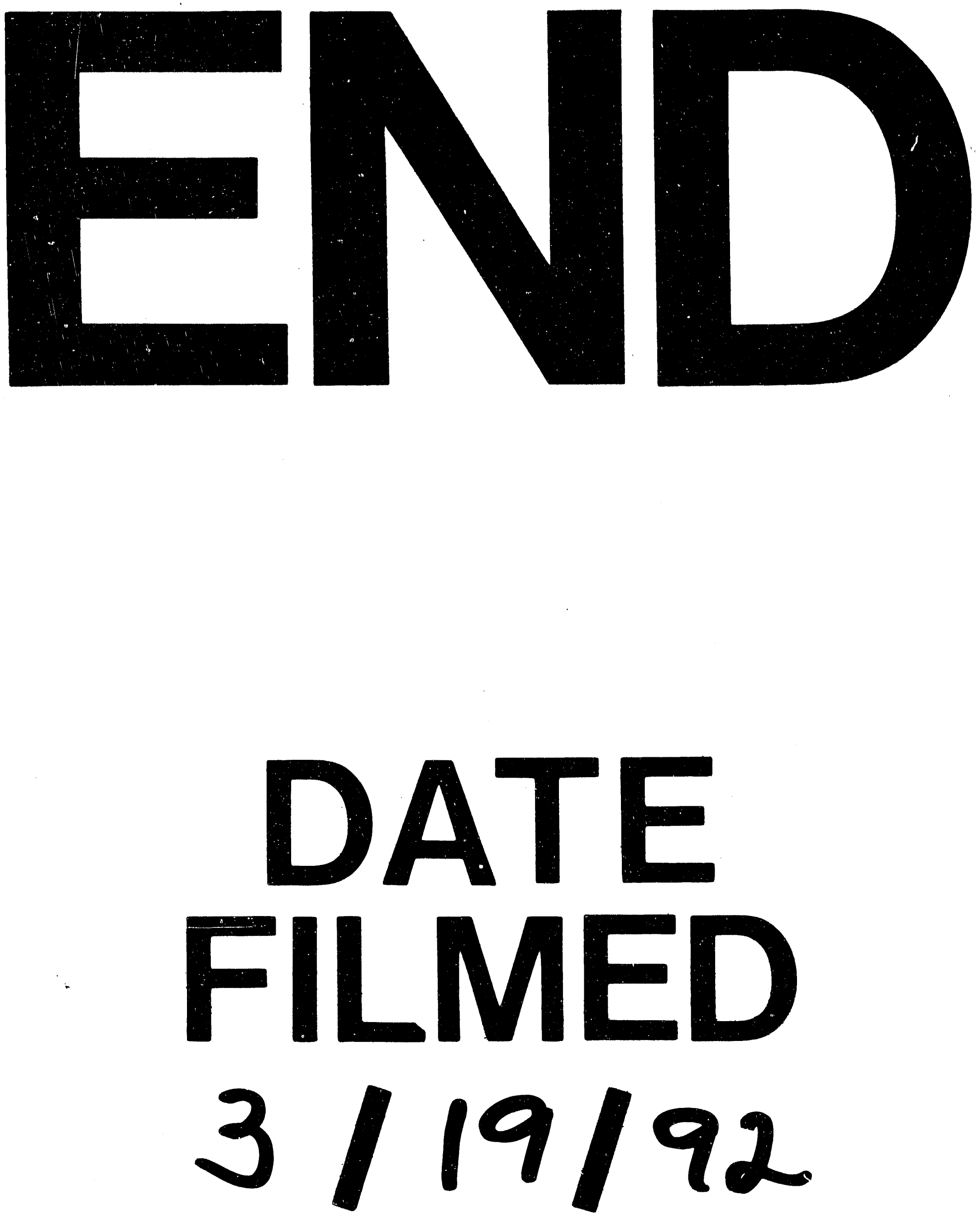
